\title{
GMR
}

\section{Study of the relationship between $I L-10$ polymorphism and serum lipoprotein levels in Han Chinese individuals}

\author{
W.Q. Yang \\ Intracardiac Second Division, \\ North China University of Science and Technology Affiliated Hospital, \\ Tangshan, China \\ Corresponding author: W.Q. Yang \\ E-mail: yangwenqi_1@163.com \\ Genet. Mol. Res. 15 (2): gmr.15028016 \\ Received December 17, 2015 \\ Accepted January 15, 2016 \\ Published June 3, 2016 \\ DOI http://dx.doi.org/10.4238/gmr.15028016
}

\begin{abstract}
Previous studies have shown that cytokines can affect serum lipoprotein concentrations. The aim of this study was to examine the association between $I L-10$ gene polymorphisms and serum lipoprotein levels of Han Chinese individuals. A total of 359 Han Chinese people were enrolled in this investigation. $I L-10-592,-819$, and -1082 genotypes were established using polymerase chain reaction-restriction fragment length polymorphism analysis. An automatic biochemistry analyzer was used to determine serum concentrations of total cholesterol (TC), triglycerides (TG), low-density lipoprotein (LDL), high-density lipoprotein (HDL), and very low-density lipoprotein (VLDL) in each individual. We observed that the three $I L-10$ polymorphisms did not significantly differ in terms of age or age of carrier $(\mathrm{P}>0.05)$, and the -592 and -819 variants did not significantly affect serum lipoprotein levels $(\mathrm{P}>0.05)$. HDL concentrations were higher and TG levels were lower in carriers of the -1082 GA genotype compared to those with the AA genotype, and these differences were statistically significant $(\mathrm{P}<0.05)$. However, TC, VLDL, and LDL levels were unaffected
\end{abstract}


by this sequence variation $(\mathrm{P}>0.05)$. Our results suggest that the polymorphism at position -1082 in the promoter region of $I L-10$ may affect serum HDL and TG concentrations, while other variants of this gene appear to have no relationship with serum lipoprotein levels.

Key words: Interleukin-10 Serum lipoprotein; Genetic polymorphism

\section{INTRODUCTION}

Plasma lipoproteins and lipids have been shown to be very important contributors to the pathophysiology of atherosclerotic vascular disease, and high levels of cholesterol, lowdensity lipoprotein (LDL), and triglycerides (TG) are considered major cardiovascular disease risk factors (Ross, 1999; Go et al., 2013). In addition, plasma levels of high-density lipoprotein (HDL) are inversely correlated with atherosclerosis risk.

A previous study has revealed that inflammatory cytokines can induce changes in lipid metabolism and lead to hyperlipidemia (Feingold et al., 1998). In contrast, metabolic disorder may affect the production, secretion, and effects of cytokines. For example, lipoproteins acting as pro-inflammatory mediators can induce the synthesis and release of inflammatory cytokines including interleukin (IL)-6, IL-1, IL-10, and NF- $\mathrm{BB}$ (Lynn et al., 2001).

According to their effects in immune and inflammatory responses, the cytokines are divided into pro- and anti-inflammatory categories. The former include IL-1 $\beta$, TNF- $\beta$, and IL-6, among others (Hashizume and Mihara, 2011). IL-6 is a key regulatory factor in inflammatory cell differentiation, and participates in the metabolism of lipids, influencing TG and LDL levels (Haddy et al., 2003; Shen et al., 2008). Therefore, it may play an important role in the inflammatory response, atherosclerosis, and thrombus formation (Haddy et al., 2003). IL-6 promoter polymorphisms might contribute to the differences between individuals in transcription of this gene and expression of the encoded protein, thus influencing its effects (Fishman et al., 1998).

The anti-inflammatory cytokine IL-10 is produced by Th2 cells and can inhibit cellular immunity and the inflammatory response (Pajkrt et al., 1997). Moreover, pro-and anti-inflammatory cytokines are capable of affecting each other. They play an important role in abnormal lipid metabolism (Nunes et al., 2008), in which they demonstrate a reciprocal relationship, and exert an effect pathophysiological processes (Huang, 2010).

Despite much evidence connecting inflammatory cytokines to lipid metabolism disorders, their relationship and the mechanism responsible remain unclear. However, cytokine promoter polymorphisms provide a novel research perspective. Therefore, this study aimed to investigate whether $I L-10$ gene polymorphisms are associated with variation in plasma lipoprotein levels.

\section{MATERIAL AND METHODS}

\section{Subjects}

A total of 359 individuals aged 23-68 years old (with an average age of $37.34 \pm 6.89$ years), comprising 195 men and 164 women examined in our hospital between June 2014 and June 2015, were enrolled in this study. All subjects were medically assessed by systematic physical examination, and blood pressure, liver and kidney function, and blood routine tests. 
In addition, their medical histories, including details of hypertension, diabetes, heart disease, and smoking and drinking habits were inspected. Subjects with significant hepatocellular, renal, or heart failure, malignant diseases, severe infection, or potential symptoms of infection for more than 4 weeks, rheumatic heart disease, or history of surgery or injury were excluded. Participants had no heredofamilial history of disease and were not genetically related. This study was approved by the relevant ethics committee, and written informed consent was obtained from all individuals.

\section{Methods}

\section{Reagents and instruments}

The following were used in this investigation: total blood DNA extraction kit (TIANGEN Biotechnology Company, Beijing, China), Taq DNA polymerase, 10X polymerase chain reaction (PCR) mix, restriction endonucleases (Thermo Fisher, Waltham, MA, USA), automatic biochemical analyzer (Beckman LX20; Beckman Coulter, Brea, CA, USA).

\section{Sample preparation}

Blood samples were obtained from all subjects in the morning following an overnight fasting. Venous blood $(5 \mathrm{~mL})$ was withdrawn from the vein into Vacutainer tubes (BD Biosciences, Franklin Lakes, NJ, USA) containing ethylenediaminetetraacetic acid as an anticoagulant. To separate plasma, blood samples were centrifuged at $3000 \mathrm{rpm}$ for $10 \mathrm{~min}$. The supernatant was used for biochemical measurements, while the buffy coat and red blood cell pellet were used for DNA extraction.

\section{Biochemical analyses}

Serum glucose, TG, total cholesterol (TC), and LDL, HDL, and very low-density lipoprotein (VLDL) cholesterol levels were measured by the standard enzymatic method, using the automatic biochemical analyzer mentioned above.

\section{Genotyping}

Genomic DNA was amplified by PCR using $I L-10$ (-592, -819, and -1082)-specific primers (Table 1). The PCR conditions used for each polymorphism are shown in Table 2. Restriction enzyme digestion was employed to determine $I L-10$ variant genotypes (Table 1 ), with the resulting fragments being analyzed on $2-2.5 \%$ agarose gels.

Table 1. Primer sequences and methods used for detection of $I L-10$ gene polymorphisms.
\begin{tabular}{l|l|l}
\hline Primer & Sequences (5'-3') & Method \\
\hline$I L-10-592$ & $\begin{array}{l}\text { Forward: 5'-CAACTTCTTCCACCCCATCTTT-3' } \\
\text { Reverse: 5'-GTGGGCTAAATATCCTCAAAGTT-3' }\end{array}$ & MaeIII-based RFLP \\
\hline$I L-10-819$ & $\begin{array}{l}\text { Forward: 5'-CAACTTCTTCCACCCCATCTTT-3' } \\
\text { Reverse: 5'-GTGGGCTAAATATCCTCAAAGTT-3' }\end{array}$ & XagI-based RFLP \\
\hline$I L-10-1082$ & $\begin{array}{l}\text { Forward: 5'-CCAAGACAACACTACTAAGGCTCCTTT-3' } \\
\text { Reverse: 5'-GCTTCTTATATGCTAGTCAGGTA-3' }\end{array}$ \\
\hline
\end{tabular}

RFLP: restriction fragment length polymorphism. 
Table 2. Polymerase chain reaction (PCR) conditions for amplification of $I L-10$ loci.

\begin{tabular}{l|l}
\hline Locus & PCR conditions \\
\hline$I L-10-592$ & $94^{\circ} \mathrm{C}(5 \mathrm{~min}) ; 35$ cycles: $94^{\circ} \mathrm{C}(45 \mathrm{~s}), 57^{\circ} \mathrm{C}(45 \mathrm{~s}), 72^{\circ} \mathrm{C}(1 \mathrm{~min}) ; 72^{\circ} \mathrm{C}(10 \mathrm{~min})$ \\
\hline$I L-10-819$ & $94^{\circ} \mathrm{C}(5 \mathrm{~min}) ; 35$ cycles: $94^{\circ} \mathrm{C}(45 \mathrm{~s}), 57^{\circ} \mathrm{C}(45 \mathrm{~s}), 72^{\circ} \mathrm{C}(1 \mathrm{~min}) ; 72^{\circ} \mathrm{C}(10 \mathrm{~min})$ \\
\hline$I L-10-1082$ & $94^{\circ} \mathrm{C}(5 \mathrm{~min}) ; 35$ cycles: $94^{\circ} \mathrm{C}(45 \mathrm{~s}), 60^{\circ} \mathrm{C}(45 \mathrm{~s}), 72^{\circ} \mathrm{C}(1 \mathrm{~min}) ; 72^{\circ} \mathrm{C}(10 \mathrm{~min})$ \\
\hline
\end{tabular}

\section{Statistical analysis}

All single nucleotide polymorphism (SNP) data were evaluated for Hardy-Weinberg equilibrium. Data are reported as medians and ranges or means and standard deviations, and were analyzed using the chi-square test and Fisher's exact test, as appropriate. Differences in the frequencies of polymorphisms between groups were compared using logistic regression analysis, while analysis of variance was used to compare serum lipid levels. All tests were two-tailed, with a confidence interval of 95\%. Statistical analysis was performed using SPSS version 20.0 (IBM Corp., Armonk, NY, USA), and P values $<0.05$ were considered statistically significant.

\section{RESULTS}

\section{IL-10 gene polymorphism}

The results of $I L-10$ polymorphism genotyping are shown in Table 3 . We found that the genotype frequencies of the three $I L-10$ variants examined conformed to Hardy-Weinberg equilibrium. Each had two alleles $(-592 \mathrm{C} / \mathrm{A},-819 \mathrm{C} / \mathrm{T}$, and $-1082 \mathrm{G} / \mathrm{A})$, and a strong allelic association between sites -592 and -819 was discerned, in that the combinations $-592 \mathrm{CC}$ and -819CC, -592CA and -819TC, and -592AA and -819TT always occurred at the same time. The -1082 GG genotype was not observed, which is consistent with a previous study (Fan et al., 2004). There were no significant differences regarding sex and age of carrier between the genotypes of the three polymorphisms $(\mathrm{P}>0.05)$.

Table 3. Genotype frequencies of polymorphisms in the $I L-10$ gene promoter region.

\begin{tabular}{l|c|c|c}
\hline Locus & \multicolumn{3}{|c}{ Genotype frequency (N) } \\
\hline-592 & AA $0.40(144)$ & AC $0.41(147)$ & CC $0.19(68)$ \\
\hline-819 & CC $0.19(68)$ & TC $0.41(147)$ & TT $0.40(144)$ \\
\hline-1082 & AA $0.92(329)$ & AG $0.08(30)$ & GG $0(0)$ \\
\hline
\end{tabular}

\section{Relationship between $I L-10$ polymorphisms and serum lipoprotein levels}

Our analysis of the relationship between the $I L-10$ gene polymorphisms under investigation and serum lipoprotein levels is shown in Table 4. No statistically significant difference was found between the -592 and -819 genotypes in terms of serum lipoprotein levels $(\mathrm{P}>0.05)$. However, HDL levels were higher and TG concentrations lower in carriers of the -1082 GA genotype than in those with an AA genotype, and these differences were statistically significant $(\mathrm{P}<0.05)$. Nonetheless, TC, VLDL, and LDL levels were unaffected by variation at this site. 
Table 4. Serum concentrations of triglycerides and lipoproteins in carriers of various $I L-10$ polymorphism genotypes (means \pm standard deviation, $\mathrm{mmol} / \mathrm{L}$.

\begin{tabular}{l|c|c|c|c|c|c}
\hline Locus & Gt & TC & TG & HDL & LDL & VLDL \\
\hline \multirow{4}{*}{-1082} & AA & $4.698 \pm 0.815$ & $1.703 \pm 1.823^{*}$ & $1.265 \pm 0.347^{*}$ & $2.406 \pm 0.582$ & $1.034 \pm 0.354$ \\
\cline { 2 - 7 } & GA & $4.973 \pm 0.915$ & $0.987 \pm 0.316^{*}$ & $1.524 \pm 0.498^{*}$ & $2.459 \pm 0.671$ & $0.983 \pm 0.138$ \\
\cline { 2 - 7 } & GG & 0 & 0 & 0 & 0 & 0 \\
\hline \multirow{5}{*}{$-819 /-592$} & CT/CA & $4.883 \pm 0.819$ & $1.899 \pm 2.394$ & $1.327 \pm 0.229$ & $2.527 \pm 0.652$ & $1.139 \pm 0.335$ \\
\cline { 2 - 7 } & CC/CC & $4.812 \pm 0.429$ & $1.294 \pm 0.548$ & $1.321 \pm 0.213$ & $2.535 \pm 0.447$ & $0.957 \pm 0.211$ \\
\cline { 2 - 7 } & TT/AA & $4.674 \pm 0.721$ & $1.684 \pm 0.802$ & $1.254 \pm 0.309$ & $2.409 \pm 0.582$ & $1.042 \pm 0.274$ \\
\hline
\end{tabular}

*Statistically significant, $\mathrm{P}<0.05 . \mathrm{Gt}=$ genotype, $\mathrm{TC}=$ total cholesterol, $\mathrm{TG}=$ triglycerides, $\mathrm{HDL}=$ high-density lipoprotein, $\mathrm{LDL}=$ low-density lipoprotein, $\mathrm{VLDL}=$ very low-density lipoprotein.

\section{DISCUSSION}

Abnormal lipid metabolism involves a complex pathology, being influenced by factors such as diet, age, occupation, environment, and metabolism (Saito, 1997). Following the development of studies in molecular genetics, the genetic basis of abnormal lipid metabolism has attracted widespread interest. The mechanism responsible for clinical cases of this disease is especially complicated, often involving gene-gene or gene-environment interactions (Kirillova, 2012).

Many studies have demonstrated that inflammatory cytokines have a close relationship with abnormal lipid metabolism (Haas and Mooradian, 2010). However, the mechanism behind this association is unclear, and prior investigations have principally concentrated on signal transduction, immune regulation, and protein expression level. In this study, healthy Han Chinese individuals were tested, and the relationship between $I L-10$ gene polymorphisms and lipid levels was investigated. Our results revealed that nucleotide variations at the -1082 site affected serum lipoprotein and lipid concentrations. Specifically, HDL and TG levels were higher and lower, respectively, in individuals with the -1082 GA genotype than in those carrying the AA genotype, implying a relationship between IL-10 and concentrations of these factors. Besides, age and sex had no significant effect on HDL or TG level. Turner et al. (1997) reported that the G allele of SNP -1082, which lies in the $I L-10$ promoter, is highly correlated with elevated IL-10 secretion.

Although our results suggest that the -592 polymorphism has no significant effect on lipid and lipoprotein levels, the TG, TC, LDL, and VLDL serum concentrations of -592 A allele carriers were higher than those of individuals harboring the $\mathrm{C}$ allele. Previous studies have also suggested that IL-10 may be involved in lipid metabolism. For instance, MiziaStec et al. (1999) reported that IL-10 concentration is significantly increased in patients with hypercholesterolemia $(\mathrm{P}<0.05)$. Moreover, in a study of the effect of IFN- $\gamma$ and IL-10 on blood lipids and glucose, Ma et al. (2004) found that IL-10 level was positively related to LDL concentration in patients with coronary diseases $(r=6.56, \mathrm{P}=0.03)$. These results reveal a relationship between IL-10 and lipid levels.

In conclusion, the $I L-10-1082$ polymorphism demonstrates a close relationship with the serum levels of certain lipoproteins and lipids, and inflammatory cytokine gene sequence variations may constitute the genetic basis of abnormal lipid metabolism and related diseases. The effects of interactions between inflammatory cytokines, cytokine polymorphisms, and lipid metabolism disorder merit further investigation. 


\section{Conflicts of interest}

The authors declare no conflict of interest.

\section{REFERENCES}

Fan LY, Zhu Y, Zhong RQ, Tu XQ, et al. (2004). Genetic association between interleukins gene polymorphisms with primary biliary cirrhosis in Chinese population. Acta Academ. Med. Sinicae 26: 505-509.

Feingold KR, Hardardóttir I and Grunfeld C (1998). Beneficial effects of cytokine induced hyperlipidemia. $Z$. Ernahrungswiss. 37 (Suppl 1): 66-74.

Fishman D, Faulds G, Jeffery R, Mohamed-Ali V, et al. (1998). The effect of novel polymorphisms in the interleukin-6 (IL-6) gene on IL-6 transcription and plasma IL-6 levels, and an association with systemic-onset juvenile chronic arthritis. J. Clin. Invest. 102: 1369-1376. http://dx.doi.org/10.1172/JCI2629

Go AS, Mozaffarian D, Roger VL, Benjamin EJ, et al.; American Heart Association Statistics Committee and Stroke Statistics Subcommittee (2013). Heart disease and stroke statistics--2013 update: a report from the American Heart Association. Circulation 127: e55-e59.http://dx.doi.org/10.1161/CIR.0b013e31828124ad

Haas MJ and Mooradian AD (2010). Regulation of high-density lipoprotein by inflammatory cytokines: establishing links between immune dysfunction and cardiovascular disease. Diabetes Metab. Res. Rev. 26: 90-99. http://dx.doi. org/10.1002/dmrr.1057

Haddy N, Sass C, Droesch S, Zaiou M, et al. (2003). IL-6, TNF-alpha and atherosclerosis risk indicators in a healthy family population: the STANISLAS cohort. Atherosclerosis 170: 277-283. http://dx.doi.org/10.1016/S00219150(03)00287-9

Hashizume M and Mihara M (2011). IL-6 and lipid metabolism. Inflamm. Regen. 31: 325-333. http://dx.doi.org/10.2492/ inflammregen.31.325

Huang LH (2010). Clinical significance of IL-1b, IL-2 and IL-10 detection in serum and prostatic fluid in chronic abacterial prostatitis pre and post treatment. Mod. Med. Health 2010-13

Kirillova OO (2012). [Modern concepts of gene polymorphisms, which regulate lipid metabolism]. Vopr. Pitan. 81: 48-52.

Lynn EG, Siow YL, Frohlich J, Cheung GT, et al. (2001). Lipoprotein-X stimulates monocyte chemoattractant protein-1 expression in mesangial cells via nuclear factor-kappa B. Kidney Int. 60: 520-532. http://dx.doi.org/10.1046/j.1523$1755.2001 .060002520 . \mathrm{x}$

Ma GT, Zhu LG, Wu B and Ma JG (2004). A study of serum concentration change of IFN-g and IL-10 of coronary heart disease and the relationship between these two cytokines and lipid and blood glucose. J. Guangxi Med. Univ. 2004: 44-46.

Mizia-Stec K, Zahorska-Markiewicz B, Mandecki T, Janowska J, et al. (1999). [The selected pro- and anti-inflammatory cytokines in the patients with coronary heart disease: preliminary communication]. Pol. Arch. Med. Wewn. 102: 677-684.

Nunes RB, Tonetto M, Machado N, Chazan M, et al. (2008). Physical exercise improves plasmatic levels of IL-10, left ventricular end-diastolic pressure, and muscle lipid peroxidation in chronic heart failure rats. J. Appl. Physiol. (1985) 104: 1641-1647.

Pajkrt D, Camoglio L, Tiel-van Buul MC, de Bruin K, et al. (1997). Attenuation of proinflammatory response by recombinant human IL-10 in human endotoxemia: effect of timing of recombinant human IL-10 administration. $J$. Immunol. 158: 3971-3977.

Ross R (1999). Atherosclerosis is an inflammatory disease. Am. Heart J. 138: S419-S420. http://dx.doi.org/10.1016/ $\underline{\mathrm{S} 0002-8703(99) 70266-8}$

Saito T (1997). Abnormal lipid metabolism and renal disorders. Tohoku J. Exp. Med. 181: 321-337. http://dx.doi. org $/ 10.1620 /$ tjem.181.321

Shen J, Arnett DK, Pérez-Martínez P, Parnell LD, et al. (2008). The effect of IL6-174C/G polymorphism on postprandial triglyceride metabolism in the GOLDN studyboxs. J. Lipid Res. 49: 1839-1845. http://dx.doi.org/10.1194/jlr. P700033-JLR200

Turner DM, Williams DM, Sankaran D, Lazarus M, et al. (1997). An investigation of polymorphism in the interleukin-10 gene promoter. Eur. J. Immunogenet. 24: 1-8. http://dx.doi.org/10.1111/j.1365-2370.1997.tb00001.x 